\title{
Mobile Phone App-Based Pulmonary Rehabilitation for Chemotherapy-Treated Patients With Advanced Lung Cancer: Pilot Study
}

Sojung Park ${ }^{1}, \mathrm{MD}, \mathrm{PhD}$; Ji Youn Kim², BSc; Jae Cheol Lee ${ }^{3}, \mathrm{MD}, \mathrm{PhD}$; Hyeong Ryul Kim ${ }^{4}$ MD, PhD; Seungjae Song ${ }^{5}, \mathrm{PhD}$; Hee Kwon ${ }^{5}$, BSc; Wonjun Ji ${ }^{1}$, MD; Chang Min Choi ${ }^{1,3}, \mathrm{MD}, \mathrm{PhD}$

\footnotetext{
${ }^{1}$ Department of Pulmonary and Critical Care Medicine, Asan Medical Center, University of Ulsan College of Medicine, Seoul, Republic of Korea

${ }^{2}$ Department of Outpatient Nursing, Asan Medical Center, Seoul, Republic of Korea

${ }^{3}$ Department of Oncology, Asan Medical Center, University of Ulsan College of Medicine, Seoul, Republic of Korea

${ }^{4}$ Department of Thoracic and Cardiovascular Surgery, Asan Medical Center, University of Ulsan College of Medicine, Seoul, Republic of Korea

${ }^{5}$ Life Semantics Corp, Seoul, Republic of Korea
}

\section{Corresponding Author:}

Chang Min Choi, MD, PhD

Department of Pulmonary and Critical Care Medicine, Asan Medical Center

University of Ulsan College of Medicine

Songpa-gu

88 Olympic-ro 43 -gil

Seoul, 05505

Republic of Korea

Phone: 82230105902

Fax: 82230106968

Email: ccm9607@gmail.com

\section{Abstract}

Background: Advanced lung cancer patients often have chronic lung disease with reduced exercise capacities and various symptoms leading to altered quality of life (QoL). No studies have assessed pulmonary rehabilitation (PR) employing a mobile app and an Internet of Things device in advanced lung cancer patients undergoing chemotherapy.

Objective: This study aimed to determine the feasibility and efficacy of smartphone app-based PR on exercise capacity, symptom management, and QoL in patients with advanced lung cancer undergoing chemotherapy.

Methods: A total of 100 patients were recruited in a prospective, single-arm intervention study using a smartphone app-based PR program for 12 weeks. Exercise capacity (6-min walking distance, 6MWD), QoL, symptom scale scores, and distress indexes were investigated.

Results: A total of 90 patients completed the PR program. The most common cause of drop out was hospitalization because of cancer progression. After PR, there was significant improvement in the 6MWD; $380.1 \mathrm{~m}$ (SD 74.1) at baseline, 429.1 $\mathrm{m}$ (SD 58.6) at 6 weeks $(P<.001)$, and $448.1 \mathrm{~m}(\mathrm{SD} 50.0)$ at 12 weeks $(P<.001)$. However, the dyspnea scale score showed no significant improvement in the patients overall, but there was a trend for improvement in those with a stable tumor response $(P=.07)$. Role $(P=.02)$, emotional $(P<.001)$, and social functioning $(P=.002)$ scale scores showed significant improvement after PR. Symptom scale scores for fatigue $(P<.001)$, anorexia $(P=.047)$, and diarrhea $(P=.01)$ also showed significant improvement. There was significant improvement in depression $(P=.048)$ and anxiety $(P=.01)$, whereas there was no significant change in QoL $(P=.06)$ and severity of pain $(P=.24)$.

Conclusions: Smartphone app-based PR represents an effective and feasible program to improve exercise capacity and to manage symptoms and distress in patients with advanced lung cancer who are undergoing chemotherapy.

(JMIR Mhealth Uhealth 2019;7(2):e11094) doi: 10.2196/11094

\section{KEYWORDS}

chemotherapy; physical fitness; lung cancer; rehabilitation; quality of life 


\section{Introduction}

\section{Background}

Lung cancer is the leading cause of death worldwide. A large number of patients are diagnosed with lung cancer in advanced stage [1]. Although the median overall survival of patients with metastatic lung cancer remains poor, advances in cancer-targeting agents and immune checkpoint inhibitors have extended life expectancy [2-6]. Patients with lung cancer often have comorbidities, such as chronic obstructive pulmonary disease (COPD) and interstitial lung disease (ILD), associated with decreased lung function and increased respiratory symptoms [7]. In addition, the adverse effects of chemotherapy and various cancer symptoms alter quality of life (QoL) and reduce the physical activity and exercise capacity of patients undergoing chemotherapy [8].

Exercise capacity is associated with lung cancer prognosis [9]. Pulmonary rehabilitation (PR) has emerged as a cost-effective intervention for managing chronic lung disease. PR improves the 6-min walking distance (6MWD), QoL, and respiratory symptoms in patients with COPD and ILD [10-13]. However, there are very limited data to demonstrate the feasibility and efficacy of PR in advanced lung cancer patients [14-17]. Currently, a large number of patients with lung cancer receive chemotherapy as outpatients. Moreover, many live in areas where an attending physician is not readily accessible. Therefore, home-based PR and symptom management is essential for patients with advanced lung cancer. The use of mobile health care may assist in overcoming these barriers, improving educational levels, facilitate frequent assessments, and allow more objective data collection $[18,19]$.

\section{Objectives}

We investigated the feasibility and efficacy of a smartphone app-based PR and educational program on exercise capacity, symptom management, and QoL in patients with advanced non-small cell lung cancer (NSCLC) undergoing chemotherapy.

\section{Methods}

\section{Participant Identification}

Consecutive patients with histologically diagnosed advanced NSCLC were identified from September to November 2016 in Asan Medical Center, Seoul, South Korea. All patients were eligible to receive palliative chemotherapy or adjuvant chemotherapy. The inclusion criteria were as follows: patients aged 20 to 75 years with (1) NSCLC stage II -IV , (2) Eastern Cooperative Oncology Group-Performance Status (ECOG-PS) $0-2$, and (3) having an android smartphone and the ability to handle the app. Patients were excluded if they (1) had concurrent malignancies other than lung cancer, (2) had received prior PR or education on lifestyle modification, (3) had symptomatic heart disease, (4) had severe cognitive impairment, and (5) were not willing to make regular visits.

Written informed consent was obtained from all patients in accordance with the Declaration of Helsinki. This study was app, was newly developed for this study. The English version of the brochure introducing the function of the app is found in Multimedia Appendix 1. Patients were provided with the Smart Aftercare app, an Internet of Things (IoT) wearable device (URBAN S, Partron Co, Seoul, Korea), which interlocked with the app, a portable pulse oximeter, thermometer, scale, and resistance bands for physical therapy.

The app engineers (Life Semantics Co, Seoul, Korea) developed the app with support from medical personnel. The app had a to-do list, individual health information, and an in-app chat service. The to-do list provided an alarm notification for daily tasks related to taking medication, performing rehabilitation exercise, and visiting the clinic on schedule. The app provided patients' laboratory results, 1 to 3 key computed tomography images, and information on the efficacy and adverse events of the chemotherapy regimen patients were receiving, as well as general lung cancer information. Through the in-app chat service, a clinical nurse specialist also provided a counseling service.

\section{Pulmonary Rehabilitation Program}

This study consisted of a 12-week rehabilitation program. The Smart Aftercare app provided an animation video on 10-min stretching exercises, 30-min aerobic exercises, 30-min muscle strengthening exercises, and 5-min finishing (stretching) exercises. Patients were instructed to run the IoT device and app during their exercise. The IoT device, which facilitates accelerometer-based activity monitoring, recorded patients' activity, including the number of steps taken and walking distance, as well as heart rate (HR). This information was transmitted to the IoT platform, developed for this study, allowing data sharing with the attending physician to check patients' condition in real time, objectively. To promote regular exercise, push notifications were sent to patients when the app had not been used for a period.

All patients performed the 6-min walk test (6MWT) every time they visited the clinic. The attending physician prescribed individualized exercise duration and intensity, which were adjusted after every clinic visit according to the results of the 6MWT. Walking, bicycle ergometer, and treadmill use were recommended. Exercise was prescribed as follows: once a day for 30 to $60 \mathrm{~min}$ at least three days a week, a walking distance target of $60 \%$ to $80 \%$ of the 6MWT, with an HR target of $70 \%$ of $\mathrm{HR}$ reserve plus resting $\mathrm{HR}$ (target $\mathrm{HR}=70 \% \mathrm{x}$ [HRmax-HRrest] + HRrest). HRmax stands for maximum HR and HRrest stands for resting HR. Patients were instructed to quit exercising if their oxygen saturation fell below $88 \%$ or they could not talk with others because of dyspnea.

The muscle strengthening exercise program comprised strengthening of all major muscle groups in the limbs and trunk. Patients were instructed to perform strengthening exercises once a day for $30 \mathrm{~min}$. Patients' muscle strength was assessed by arm abduction test, 10 times. Various resistance bands with different

\section{A comprehensive mobile health care app, the Smart Aftercare}


intensities were provided according to patients' muscle strength. The app and IoT device checked whether the patient completed daily exercise tasks and gave feedback on the amount of activity and calories expended in a day.

\section{Symptom Management}

The Smart Aftercare app provided an animation video on pain control, nutritional support, and symptom management. Furthermore, algorithms for the management of pain and adverse skin reactions, a frequently asked questions service, were also provided. Patients were instructed to record daily body weight and temperature on the app.

\section{Data Collection}

Demographic information was investigated at baseline, and the relevant medical data were collected from medical records. Patients visited the clinic every 4 or 6 weeks, depending on their schedule of chemotherapy (Table 1). At visits, they completed the questionnaires for QoL, symptom (the European Organization for Research and Treatment of Cancer Quality of Life Questionnaire-C30, EORTC QLQ-C30), pain (numeric rating scale, NRS), and distress, including anxiety (Generalized Anxiety Disorder-7, GAD-7) and depression (Patient Health Questionnaire-9, PHQ-9). We also evaluated service satisfaction using a self-developed questionnaire (Multimedia Appendix 2). For patients who visited the clinic every 4 weeks, the mean value of each scale at 4 and 8 weeks was used for investigation at midterm assessment. Permission to use the EORTC QLQ-C30 was obtained, and the authorized Korean version of the questionnaire was freely downloadable from the internet. No permission was required for NRS, PHQ-9, or GAD-7.

\section{Unexpected Visits to the Emergency Department}

As we performed a single-arm study using a mobile app, this study was limited in that it had no control group. Therefore, we retrospectively evaluated the number of unexpected visits to the emergency department (ED) comparing patients who participated in this study with those who did not. The number of visits to the ED is widely regarded as an indicator of the development of unexpected, uncontrolled symptoms. We expected that the mobile app could provide information regarding how to manage symptoms through an algorithm and in-app chat service, thereby reducing medical expenses and time. From September to November 2016, a total of 1091 patients underwent chemotherapy in Asan Medical Center. Of these, 100 patients participated in this study, whereas 991 did not. Their electrical medical records were retrospectively reviewed.

Table 1. Assessment schedule.

\begin{tabular}{|c|c|c|c|}
\hline Schedule & Screening & 4,8 , or 6 weeks $( \pm 1 \text { week })^{\mathrm{a}}$ & 12 weeks $( \pm 1 \text { week })^{\mathrm{a}}$ \\
\hline Informed consent & $\checkmark^{\mathrm{b}}$ & $-^{c}$ & - \\
\hline Demographic characteristics & $\checkmark$ & - & - \\
\hline Inclusion or exclusion criteria & $\checkmark$ & - & - \\
\hline Vital signs and oxygen saturation & $\checkmark$ & $\checkmark$ & $\checkmark$ \\
\hline Physical examination & $\checkmark$ & $\checkmark$ & $\checkmark$ \\
\hline History taking & $\checkmark$ & - & - \\
\hline Disease status evaluation $^{\mathrm{d}}$ & $\checkmark$ & $\checkmark$ & $\checkmark$ \\
\hline Satisfaction questionnaire for the Aftercare app & - & - & $\checkmark$ \\
\hline 6-min walk test and exercise prescription & $\checkmark$ & $\checkmark$ & $\checkmark$ \\
\hline EORTC QLQ-C30 & $\checkmark$ & - & $\checkmark$ \\
\hline Numeric pain rating scale & $\checkmark$ & $\checkmark$ & $\checkmark$ \\
\hline GAD- $7^{f}$ & $\checkmark$ & $\checkmark$ & $\checkmark$ \\
\hline PHQ-9g & $\checkmark$ & $\checkmark$ & $\checkmark$ \\
\hline Assessment for adverse reaction of chemotherapy & - & $\checkmark$ & $\checkmark$ \\
\hline
\end{tabular}

${ }^{\mathrm{a}} 1$ week before and after the visiting day was allowed.

${ }^{\mathrm{b}}$ Data were obtained at the time marked with a check.

${ }^{\mathrm{c}}$ Data not obtained at the time marked with an dash.

${ }^{\mathrm{d}}$ Treatment response was assessed at least once in all patients during the study period depending on their schedule of chemotherapy.

${ }^{\mathrm{e}}$ EORTC QLQ-C30: European Organization for Research and Treatment of Cancer Quality of Life Questionnaire-C30.

${ }^{\mathrm{f}} \mathrm{GAD}-7$ : Generalized Anxiety Disorder-7.

${ }^{\mathrm{g}}$ PHQ-9: Patient Health Questionnaire-9. 


\section{Statistical Analysis}

Categorical variables were analyzed using Pearson chi-square test or Fisher exact test. Continuous variables were analyzed using a Student $t$ test. A paired $t$ test and Bonferroni correction were used for comparison of pre- and post-PR assessment. All tests of significance were two sided, and differences between groups were considered to be significant when the $P$ value was $<.05$. All statistical analyses were performed with SPSS software version 22.0 (IBM Corp, Armonk, NY).

\section{Results}

\section{Patients}

A total of 100 patients were enrolled, and 90 patients completed the 12-week rehabilitation program. The baseline characteristics of the patients are presented in Table 2. The mean age of the patients was 55.1 years (SD 8.7); 46.0\% (46/100) were males. The most common cause of drop out was hospitalization because of cancer progression $(6 / 100,6.0 \%)$, followed by transfer to other hospitals $(2 / 100,2.0 \%)$ and difficulty in handling the app (2/100, 2.0\%). Patients who had completed the PR program had a significant higher baseline body mass index and better performance status than patients who had dropped out.

\section{Exercise Capacity}

The mean exercise number per week was 3.8 (SD 1.2) at 1 week, 4.2 (SD 1.1) at 6 weeks, and 4.1 (SD 1.2) at 12 weeks, satisfying the exercise prescription. A total of 85 patients completed all 6MWTs according to the schedule. In addition to 10 patients who dropped out, 5 patients refused to perform 6MWT because of general weakness, paraplegia, knee pain, and dizziness. There was significant difference in the baseline 6MWD according to baseline ECOG-PS. The mean distance was $416.8 \mathrm{~m}$ (SD 55.4) in patients with ECOG-PS 0, $369.8 \mathrm{~m}$ (SD 80.3) in those with ECOG-PS 1, and $305.7 \mathrm{~m}$ (SD 89.1) in those with ECOG-PS $2(P=.04)$. After PR, the 6MWD had improved significantly: $380.1 \mathrm{~m}(\mathrm{SD} 74.1)$ at baseline, $429.1 \mathrm{~m}(\mathrm{SD} 58.6, P<.001)$ at 6 weeks, and $448.1 \mathrm{~m}(\mathrm{SD} 50.0, P<.001)$ at 12 weeks (Figure 1). We investigated the exercise capacity depending on their treatment response. Consequently, patients with stable disease showed significantly improved 6MWD: $384.2 \mathrm{~m}$ (SD 74.6) at baseline, $426.1 \mathrm{~m}(\mathrm{SD} 6.5, P<.001)$ at 6 weeks, and $447.4 \mathrm{~m}$ (SD 50.4, $P<.001$ at 12 weeks (Figure 1). However, exercise capacity remained unimproved in patients with progressive disease. The dyspnea scale, evaluated using the EORTC QLQ-C30, did not show any significant improvement in the patients overall, but patients with stable disease tended to improve.

\section{Quality of Life, Functional, and Symptom Scales}

Of 90 patients who completed the study, 86 patients completed all questions in the questionnaire EORTC QLQ-C30. The EORTC QLQ-C30 consists of a global health status and QoL scale, functional scales, and symptom scales. Global health status and QoL tended to improve in patients overall, although not statistically significant (Table 3), whereas all functional scales, except the cognitive scale, improved significantly after PR. Symptom scales, in which a high score represents more severe symptoms, for fatigue, appetite loss, and diarrhea showed significant improvement in patients overall. In patients with stable disease, global health status and QoL scale did not improve significantly. Nevertheless, similar improvement in functional and symptom scales were observed in these patients as in the patients overall.

\section{Pain Control}

Overall, the pain severity significantly decreased at 6 weeks: 1.7 (SD 2.2) at baseline and 1.2 (SD 1.8, $P=.02)$ at 6 weeks, but not at 12 weeks (mean 1.4, SD 1.9; $P=.20$; Figure 2). In patients with stable disease, the NRS score tended to improve at 6 weeks: 1.7 (SD 2.2) at baseline and 1.2 (SD 2.0, $P=.06)$ at 6 weeks, but not at 12 weeks (mean 1.5, SD 1.9; $P=.79$ ).

\section{Distress Index}

Overall, baseline distress indexes showed mild anxiety and depression (Figure 3). Low indexes represent less distress. Anxiety significantly improved at 12 weeks: 3.9 (SD 4.1; baseline), 3.4 (SD 3.7; 6 weeks $P=.11$ ), 2.4 (SD 3.8; 12 weeks, $P<.001$; Figure 3). Depression worsen at 6 weeks: 4.7 (SD 4.9; baseline), 5.0 (SD 5.2; 6 weeks, $P=.44$ ), but significantly improved at 12 weeks (mean 3.5, SD 4.5; $P=.02$; Figure 3 ). Only the depression index was associated with the treatment response $(P=.04)$.

\section{Service Satisfaction}

Of 90 patients who completed the PR program, 69 (69/90, 77\%) patients reported that they were satisfied with the service and $79(79 / 90,88 \%)$ reported that they would recommend it to others. Neither age nor home region affected on service satisfaction. A total of $86(86 / 90,96 \%)$ patients reported that they were paying more attention to their health or disease status since using the app. In addition, all patients reported that the management algorithms for adverse events were helpful for controlling symptoms and determining when to visit the hospital. Patients who reported dissatisfaction with the service mostly cited difficulty in handling the app and frequent system error.

\section{Unexpected Visits to the Emergency Department}

Of 991 patients who did not participate in this study, 302 $(302 / 991,30.5 \%)$ visited the ED. However, 15 (15/100, 15.0\%) of 100 patients included in this study visited the ED during the same period; this indicated a significant reduction in frequency $(P=.001)$. The baseline characteristics, such as sex and tumor stage, were not significantly different between 2 groups; baseline age was more in patients who did not participate in the study than in patients who did (62.9 years, SD 10.3 vs 55.2 years, SD $8.7 ; P=.03)$. However, there was no significant difference in age between patients who visited the ED and those who did not (62.6 years, SD 10.6 vs 63.0 years, SD $0.2 ; P=.71$ ). 
Table 2. Baseline characteristics of patients who participated in the mobile comprehensive rehabilitation program.

\begin{tabular}{lllll}
\hline Baseline characteristics & Total $(\mathrm{N}=100)$ & Complete $(\mathrm{n}=90)$ & Interrupted (n=10) & $P$ value \\
\hline Age in years, mean $(\mathrm{SD})$ & $55.1(8.7)$ & $54.9(8.8)$ & $56.8(7.7)$
\end{tabular}

Sex, n (\%)

Male

History of smoking, $n(\%)$

Current smoker

Ex-smoker

Never smoker

$\mathrm{ECOG}^{\mathrm{b}}, \mathbf{n}(\%)$

Zero

Time of diagnosis of lung cancer, $n(\%)$

Within 1 year

Within 1-2 years

Within 2-3 years

$>2$ years

Stage, $\mathbf{n}(\%)$

II

III

IV

Lung function, mean (SD)

$\mathrm{FVC}^{\mathrm{c}}(\%)$

$\mathrm{FEV}_{1}{ }^{\mathrm{d}}(\%)$

Diffusing lung capacity (\%)

Line of chemotherapy, n (\%)

First

Second

Third and more

Adjuvant

Histology, n (\%)

Adenocarcinoma

Squamous cell carcinoma

Others

Regimen of chemotherapy, n (\%)

Tyrosine kinase inhibitor

Platinum-based chemotherapy

Others

Response rate $^{\mathrm{e}}, \mathrm{n}(\%)$

Complete response

Partial response

$\begin{array}{lll}46(46.0) & 41(46) & 5(50) \\ 24.2(3.5) & 24.4(3.5) & 22.0(1.8) \\ 11(11.0) & 9(10) & 2(20) \\ 28(28.0) & 26(29) & 2(20) \\ 61(61.0) & 55(61) & 6(60)\end{array}$

$\begin{array}{lll}13(13.0) & 11(12) & 2(20) \\ 83(83.0) & 77(86) & 6(60) \\ 4(4.0) & 2(2) & 2(20)\end{array}$

.82

$\begin{array}{lll}56(56.0) & 49(54) & 7(70) \\ 16(16.0) & 15(17) & 1(10) \\ 16(16.0) & 15(17) & 1(10) \\ 12(12.0) & 11(12) & 1(10)\end{array}$

(70)

(10)

$1(10)$

$5(5.0)$

$5(6)$

$>.99$

$0(0.0)$

$0(0)$

$0(0)$

95 (95.0)

$10(100)$

$0(0)$

85 (94)

$\begin{array}{llll}84.2(17.7) & 84.4(17.3) & 82.3(23.6) & .79 \\ 80.7(19.2) & 80.9(19.3) & 79.2(19.5) & .84 \\ 82.2(15.1) & 82.8(15.0) & 73.3(15.2) & .22 \\ & & & .76\end{array}$

$73(73.0) \quad 66(73) \quad 7(70)$

$12(12.0) \quad 10(11) \quad 2(20)$

$10(10.0) \quad 9(10) \quad 1(10)$

$5(5.0) \quad 5(6) \quad 0$

$\begin{array}{lll}94(94.0) & 84(93) & 10(100) \\ 4(4.0) & 4(4) & 0 \\ 2(2.0) & 2(2) & 0\end{array}$

$\begin{array}{lll}40(40.0) & 36(40) & 4(40) \\ 38(38.0) & 35(39) & 3(30) \\ 22(22.0) & 19(21) & 3(30)\end{array}$

.78

.001 


\begin{tabular}{clll}
\hline Baseline characteristics & Total $(\mathrm{N}=100)$ & Complete $(\mathrm{n}=90)$ & Interrupted $(\mathrm{n}=10)$ \\
\hline Stable disease & $69(69.0)$ & $66(73)$ & $3(30)$ \\
Progressive disease & $16(16.0)$ & $10(11)$ & $6(60)$ \\
\hline
\end{tabular}

${ }^{\mathrm{a}} \mathrm{BMI}$ : body mass index.

${ }^{\mathrm{b}}$ ECOG: Eastern Cooperative Oncology Group.

${ }^{\mathrm{c}} \mathrm{FVC}$ : forced vital capacity.

${ }^{\mathrm{d}} \mathrm{FEV}_{1}$ : forced expiratory volume in 1 second.

${ }^{\mathrm{e}}$ Disease response was evaluated using response evaluation criteria in solid tumors criteria in patients with stage IV lung cancer. We considered patients with stage II lung cancer to have stable disease status.

Figure 1. Exercise capacity. Six-minute walking distance improved significantly after pulmonary rehabilitation in the patients overall (A) and patients with stable tumor response (B).
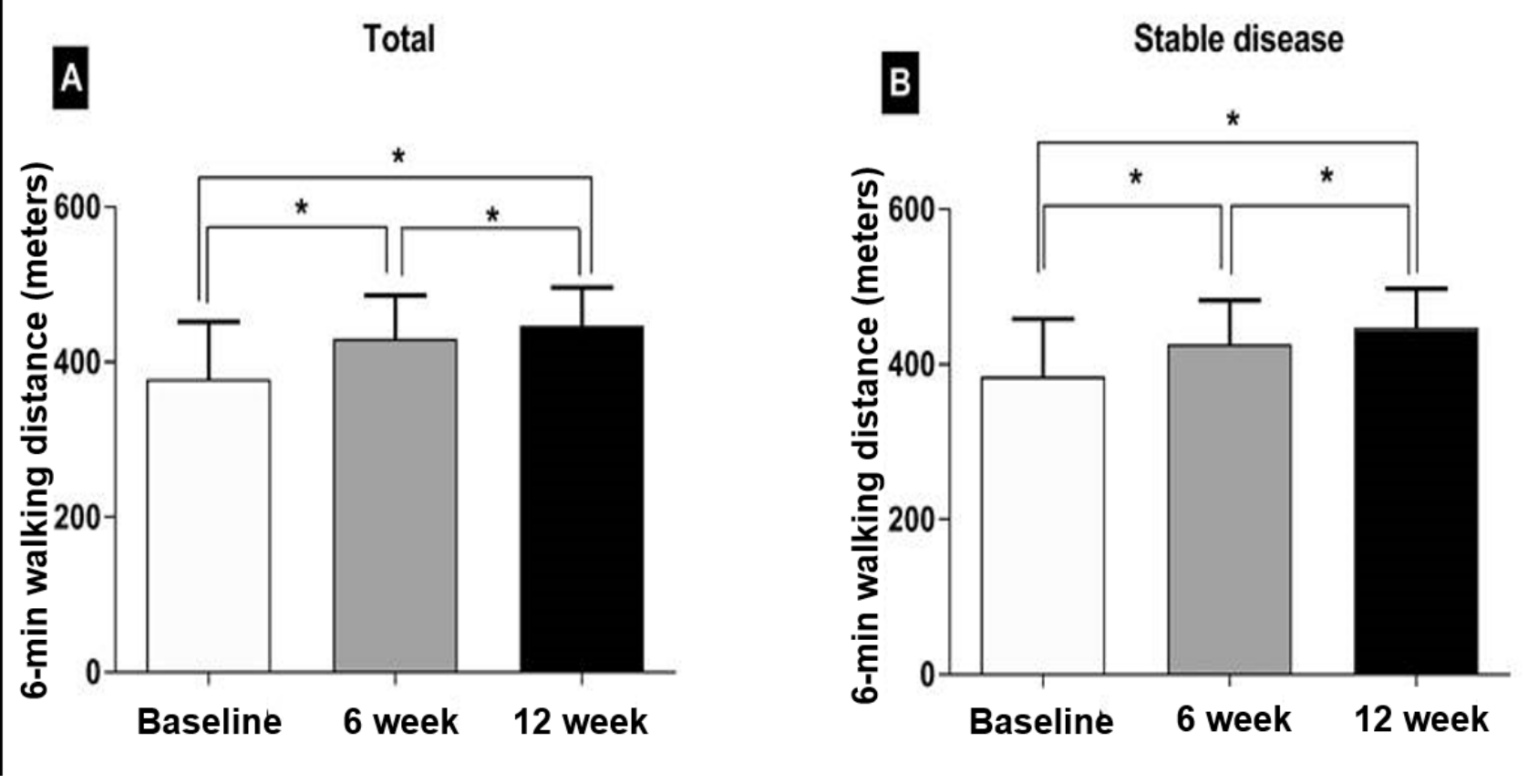
Table 3. Quality of life, functional, and symptom scale.

\begin{tabular}{|c|c|c|c|c|c|c|c|c|c|}
\hline \multirow[t]{2}{*}{ EORTC QLQ-C30 ${ }^{\mathrm{a}}$} & \multicolumn{3}{|l|}{ Total $(\mathrm{n}=86)$} & \multicolumn{3}{|c|}{ Stable disease $(n=65)$} & \multicolumn{3}{|c|}{ Progressive disease $(n=7)$} \\
\hline & $\begin{array}{l}\text { Baseline, } \\
\text { mean (SD) }\end{array}$ & $\begin{array}{l}12 \text { week, } \\
\text { mean }(\mathrm{SD})\end{array}$ & $P$ value & $\begin{array}{l}\text { Baseline, } \\
\text { mean (SD) }\end{array}$ & $\begin{array}{l}12 \text { week, } \\
\text { mean }(\mathrm{SD})\end{array}$ & $P$ value & $\begin{array}{l}\text { Baseline, } \\
\text { mean (SD) }\end{array}$ & $\begin{array}{l}12 \text { week, } \\
\text { mean }(\mathrm{SD})\end{array}$ & $P$ value \\
\hline $\begin{array}{l}\text { Global health status or } \\
\text { QoL }^{\text {b }} \text { scale }\end{array}$ & $64.1(24.7)$ & $69.3(21.2)$ & .06 & $66.3(22.0)$ & 70.5 (19.7) & .15 & $53.6(35.0)$ & $67.9(26.5)$ & .24 \\
\hline \multicolumn{10}{|l|}{ Functional scales } \\
\hline Physical functioning & $78.2(14.3)$ & $81.1(15.7)$ & .06 & $77.6(14.5)$ & $81.2(15.5)$ & .06 & $79.0(18.2)$ & $77.1(20.7)$ & .63 \\
\hline Role functioning & $75.0(22.8)$ & $81.4(23.3)$ & .02 & $75.6(22.5)$ & $82.1(23.4)$ & .048 & $73.8(30.2)$ & $73.8(33.1)$ & $>.99$ \\
\hline Emotional functioning & 73.7 (19.6) & $83.7(18.7)$ & $<.001$ & $74.9(18.8)$ & $82.9(19.2)$ & .002 & $76.2(21.2)$ & $86.9(19.8)$ & .33 \\
\hline Cognitive functioning & $81.4(15.8)$ & $83.9(18.7)$ & .25 & $81.3(15.5)$ & $82.8(20.2)$ & .54 & $88.1(18.5)$ & $85.7(17.8)$ & .82 \\
\hline Social functioning & $74.6(25.1)$ & $82.8(20.2)$ & .002 & $73.6(25.5)$ & $83.3(20.2)$ & .001 & $73.8(23.3)$ & $83.3(21.5)$ & .23 \\
\hline \multicolumn{10}{|l|}{ Symptom scales } \\
\hline Fatigue & $35.7(21.2)$ & $27.1(22.3)$ & $<.001$ & $35.0(22.1)$ & $26.8(22.2)$ & .001 & $36.5(24.6)$ & $34.9(29.0)$ & .86 \\
\hline Nausea or vomiting & $8.9(15.9)$ & $10.5(14.7)$ & .45 & $8.2(15.6)$ & $10.8(15.4)$ & .27 & $9.5(13.1)$ & $7.1(8.9)$ & .36 \\
\hline Pain & $20.2(20.9)$ & $22.9(23.6)$ & .33 & $19.0(21.4)$ & $25.4(24.7)$ & .06 & $23.8(16.3)$ & $14.3(15.0)$ & .23 \\
\hline Dyspnea & $26.7(23.3)$ & $25.2(25.0)$ & .56 & $27.2(22.7)$ & $25.6(23.4)$ & .07 & $19.0(26.2)$ & $38.1(44.8)$ & .10 \\
\hline Insomnia & $26.0(28.2)$ & $21.3(28.0)$ & .12 & $25.1(29.5)$ & $22.1(27.2)$ & .39 & $19.0(32.5)$ & $28.6(48.8)$ & .17 \\
\hline Appetite loss & $21.7(25.4)$ & $16.3(21.5)$ & .047 & $21.5(24.6)$ & $14.9(21.3)$ & .03 & $33.3(38.5)$ & $19.0(26.2)$ & .20 \\
\hline Constipation & $15.5(23.8)$ & $17.1(23.3)$ & .65 & $16.4(25.8)$ & $15.9(22.9)$ & .90 & $14.3(17.8)$ & $23.8(25.2)$ & .36 \\
\hline Diarrhea & $19.4(26.8)$ & $11.6(19.6)$ & .01 & $21.0(28.6)$ & $10.8(17.8)$ & .01 & $28.6(23.0)$ & $14.3(26.2)$ & .08 \\
\hline Financial difficulties & $24.8(26.2)$ & $21.3(25.0)$ & .14 & $26.7(27.8)$ & $21.5(25.3)$ & .049 & $28.6(23.0)$ & $19.0(26.2)$ & .36 \\
\hline
\end{tabular}

${ }^{a}$ EORTC QLQ-C30: European Organization for Research and Treatment of Cancer Quality of Life Questionnaire-C30.

${ }^{\mathrm{b}} \mathrm{QoL}$ : quality of life.

Figure 2. Pain scale. The pain severity, assessed by numeric rating scale, significantly decreased at 6 weeks but increased at 12 weeks (A). There was no significant improvement in patients with stable tumor response (B).
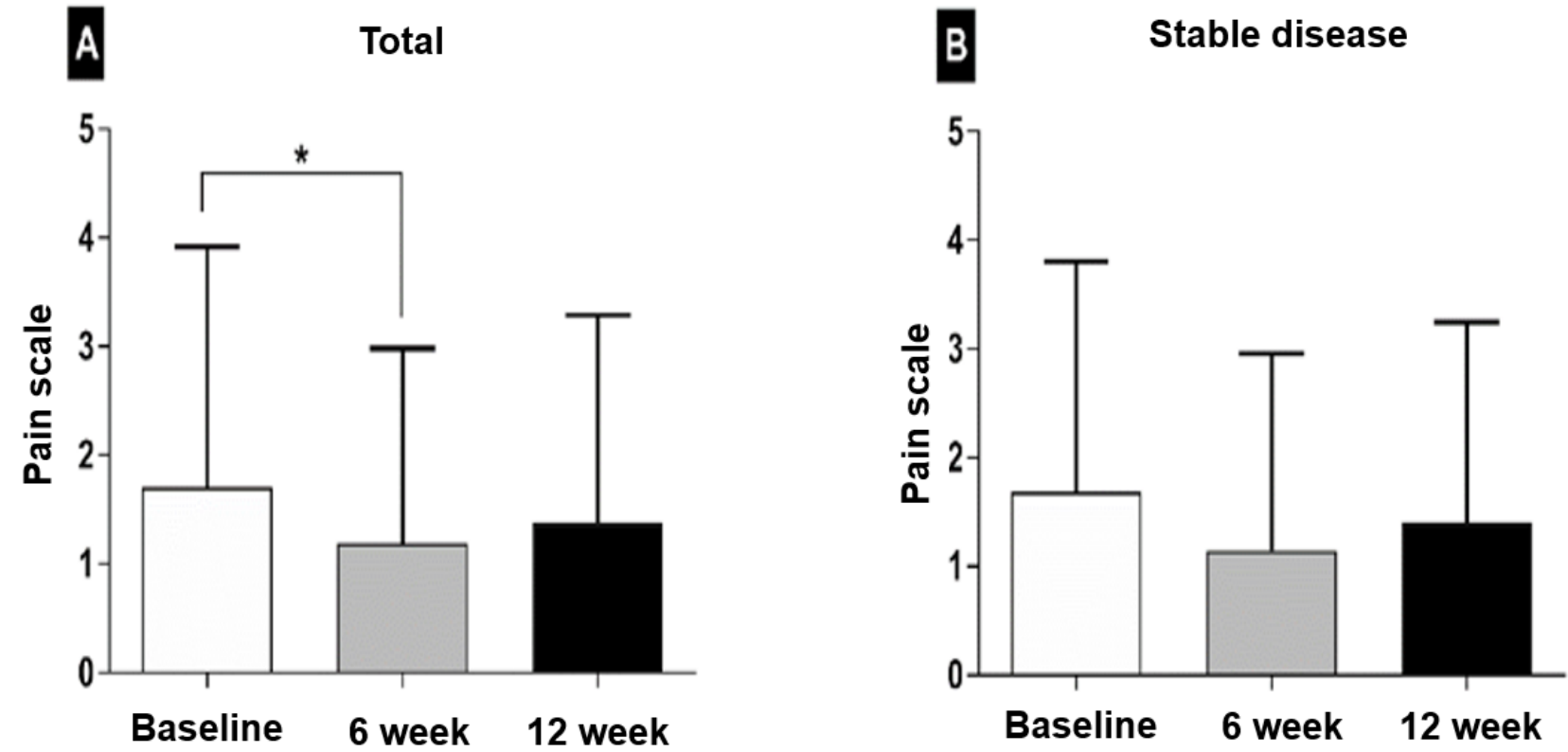
Figure 3. Distress indexes. Anxiety (A) and depression (B) significantly improved after pulmonary rehabilitation.

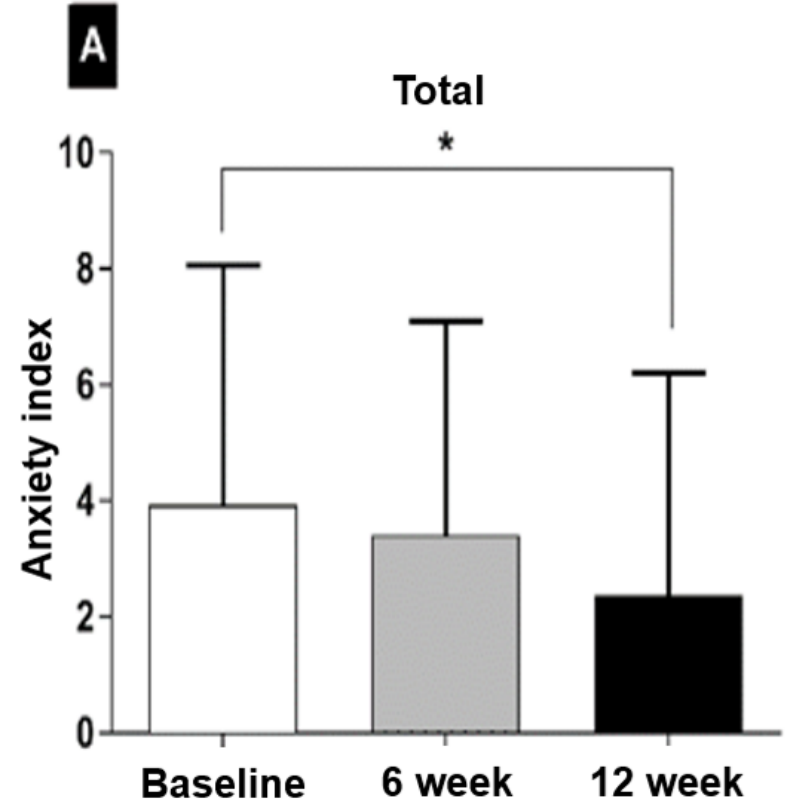

\section{Discussion}

\section{Principal Findings}

The 12-week Smart Aftercare PR program provided comprehensive management of common challenges of patients with advanced lung cancer. To the best of our knowledge, this is the first study that demonstrated the feasibility and efficacy of smartphone app-based PR for improving exercise capacity and symptoms in patients with advanced NSCLC during chemotherapy.

Because many lung cancer patients are elderly, there is some concern about difficulty in handling a smartphone app. However, only 2 patients ceased participation for this reason. The most important cause of drop out was cancer progression. A total of 16 patients suffered from cancer progression during the 12 weeks' PR program, and 2 patients died. Patients with advanced cancer will unavoidably suffer symptomatic deterioration with disease progression. However, exercise capacity, functional status, various symptoms, and distress indexes significantly improved in patients with stable disease. The objective response rate to estimated glomerular filtration rate tyrosine kinase inhibitors exceeds $70 \%$, and the median duration of response to an immune checkpoint inhibitor is 10 to 25 months $[2,3,5,6]$. Therefore, the role of PR in advanced NSCLC seems increasingly important.

Exercise capacity is associated with advanced lung cancer prognosis [9]. Multiple small trials have demonstrated the benefit of hospital-based and home-based PR in patients with advanced lung cancer [14-17]. However, no studies have assessed PR employing a mobile app. The 6MWD significantly improved after PR in patients overall as well as in patients with stable disease. Although the dyspnea scale was not significantly improved, it tended to improve in patients with stable disease.

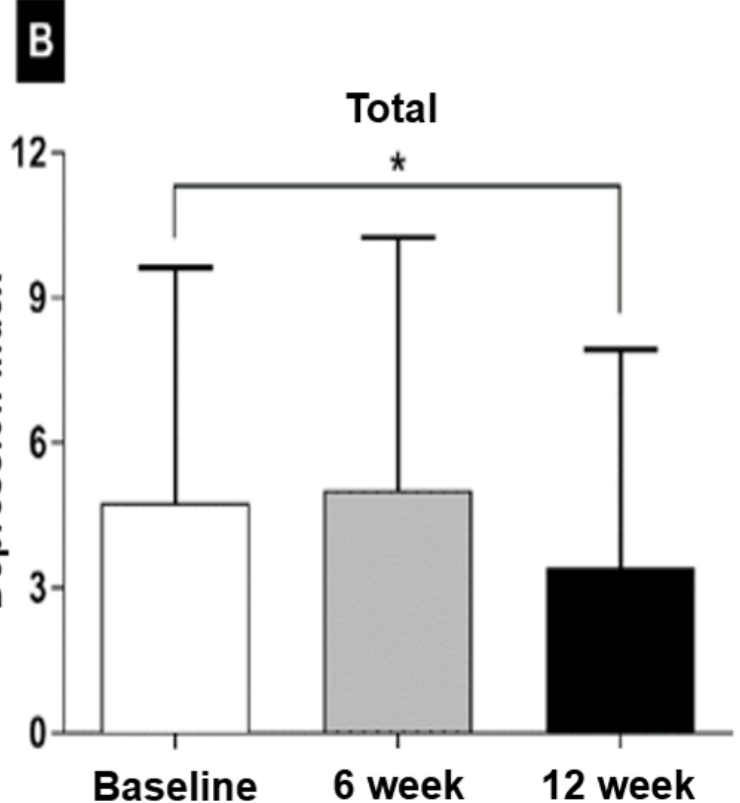

Baseline performance status was significantly associated with baseline 6MWD but not with changes in absolute distance. Rather, patients with ECOG-PS 1 showed a mean increase in walking distance of $17 \mathrm{~m}$ more as compared with patients with ECOG-PS 0. One patient with ECOG-PS 2 showed an increase in walking distance of $132 \mathrm{~m}$ after the 12-week PR. Therefore, PR should be recommended to patients regardless of their disease status or PS, if feasible.

Smartphone-based PR provided significant improvement in functional scales, symptomatic scales, and distress indexes. Of 90 patients who completed the PR program, 86 (86/90, 96\%) patients reported that smartphone-based PR promoted behavioral changes and facilitated self-monitoring of symptoms. This might have affected functional scale improvement, especially emotional scales and distress indexes. In addition, Shallwani et al reported that 6MWT distance was the predictor of change in the mental component of QoL. Therefore, improvement of exercise capacity affected emotional scales and distress indexes [20]. Moreover, 73 (73/90, 81\%) patients reported that they felt that they were in contact with their health care team. Indeed, 78 (78/100, 78.0\%) patients enrolled in this study lived outside of Seoul. This approach might be useful for patients living in areas where an attending physician is not readily accessible. Patients who participated in this study had significantly fewer ED visits than patients who did not participate in the study. In addition, there were no adverse events related to the smartphone-based PR, such as condition deterioration because of immoderate exercise or medicine overdose.

Anxiety and depression were significantly improved at 12 weeks. Depression was associated with the treatment response. In subgroup analysis, patients who received first-line chemotherapy showed a subsequent reduction in depression index, with a significant reduction in score at 12 weeks (5.6 [SD 5.8] at baseline, 5.5 [SD 5.8] at 6 weeks, and 3.5 [SD 4.8] 
at 12 weeks; $P=.04)$. Furthermore, patients who received second-line chemotherapy and beyond showed higher depression index at 6 weeks (4.1 [SD 3.0] at baseline vs 5.3 [SD 5.6] at 6 weeks; $P=.24$ ) but lower index at 12 weeks (3.4 [SD 3.9], $P=.33$ ). Therefore, disease status and duration of illness were important factors in the distress index.

QoL and severity of pain were not significantly improved through PR. Pain is a key factor affecting QoL in patients with lung cancer [21]. We provided various kinds of services to help reduce pain, but they were ineffective. Therefore, selfmanagement of pain using a smartphone app is insufficient and frequent assessment and physical examination at a clinic is needed. In contrast, treatment response, an important factor affecting health-related QoL, showed no significant association with QoL in this study [22].

\section{Limitations}

This study has several limitations. First, there was no control group. Uhm et al reported that mobile health management did not show significant superiority over a conventional program in terms of physical function in patients with breast cancer [23]. However, the lungs are strongly associated with dyspnea and exercise capacity, and the usefulness of home-based PR for chronic lung diseases and lung cancer has previously been reported $[17,24,25]$. Further randomized controlled studies are needed to prove the superiority of the smartphone app-based PR over conventional education. Second, a small number of patients with heterogeneous disease status were included. In addition, the influence of the different chemotherapy regimens, which are associated with different adverse reactions that influence symptoms and QoL, was not considered. Third, monitoring of the amount and intensity of exercise relied on the IoT device only. If the IoT device had a systemic error, all data gathered on the IoT platform are unreliable. However, several studies have demonstrated the viability of a smartphone for step counting or gait analysis, and thus, they can be used to automate the 6MWT [26-29].

\section{Conclusions}

In conclusion, 12 weeks of comprehensive smartphone app-based individualized PR seems to be an effective and feasible approach for improving exercise capacity, symptom management, and distress in patients with advanced NSCLC undergoing systemic chemotherapy.

\section{Acknowledgments}

This work was supported by the National Information Society Agency funded by the Ministry of Science and Information and Communication Technology (Grant number: 2016-0-00586).

\section{Authors' Contributions}

CMC and SP had full access to all of the data in the study and take responsibility for the integrity of the data and the accuracy of the data analysis. CMC contributed to the design of the study and final approval of the paper. SP contributed to data analysis and drafting the paper. JYK provided counseling service through the app. JCL, HRK, and WJ contributed to subject recruitment and offered counsel for development of the app. SS and HK contributed to develop the app and IoT platform.

\section{Conflicts of Interest}

SS and HK are employed by LifeSemantics. LifeSemantics developed the Aftercare and owns full right to use it for commercial purposes as fit by the company.

\section{Multimedia Appendix 1}

The English version of the brochure introducing the function of the Aftercare app.

[PNG File, 383KB-Multimedia Appendix 1]

\section{Multimedia Appendix 2}

Questionnaire for service quality and satisfaction.

[PDF File (Adobe PDF File), 153KB-Multimedia Appendix 2]

\section{References}

1. Park JY, Jang SH. Epidemiology of lung cancer in Korea: recent trends. Tuberc Respir Dis (Seoul) 2016 Apr;79(2):58-69 [FREE Full text] [doi: 10.4046/trd.2016.79.2.58] [Medline: 27064578]

2. Mok TS, Wu Y, Thongprasert S, Yang CH, Chu DT, Saijo N, et al. Gefitinib or carboplatin-paclitaxel in pulmonary adenocarcinoma. N Engl J Med 2009 Sep 03;361(10):947-957. [doi: 10.1056/NEJMoa0810699] [Medline: 19692680]

3. Maemondo M, Inoue A, Kobayashi K, Sugawara S, Oizumi S, Isobe H, North-East Japan Study Group. Gefitinib or chemotherapy for non-small-cell lung cancer with mutated EGFR. N Engl J Med 2010 Jun 24;362(25):2380-2388. [doi: 10.1056/NEJMoa0909530] [Medline: 20573926] 
4. Chang YS, Choi C, Lee JC. Mechanisms of epidermal growth factor receptor tyrosine kinase inhibitor resistance and strategies to overcome resistance in lung adenocarcinoma. Tuberc Respir Dis (Seoul) 2016 Oct;79(4):248-256 [FREE Full text] [doi: $10.4046 /$ trd.2016.79.4.248] [Medline: 27790276$]$

5. Herbst RS, Baas P, Kim DW, Felip E, Pérez-Gracia JL, Han JY, et al. Pembrolizumab versus docetaxel for previously treated, PD-L1-positive, advanced non-small-cell lung cancer (KEYNOTE-010): a randomised controlled trial. Lancet 2016 Apr 09;387(10027):1540-1550. [doi: 10.1016/S0140-6736(15)01281-7] [Medline: 26712084]

6. Horn L, Spigel DR, Vokes EE, Holgado E, Ready N, Steins M, et al. Nivolumab versus docetaxel in previously treated patients with advanced non-small-cell lung cancer: two-year outcomes from two randomized, open-label, phase III trials (CheckMate 017 and CheckMate 057). J Clin Oncol 2017 Dec 10;35(35):3924-3933. [doi: 10.1200/JCO.2017.74.3062] [Medline: 29023213]

7. de Torres JP, Marín JM, Casanova C, Cote C, Carrizo S, Cordoba-Lanus E, et al. Lung cancer in patients with chronic obstructive pulmonary disease--incidence and predicting factors. Am J Respir Crit Care Med 2011 Oct 15;184(8):913-919. [doi: 10.1164/rccm.201103-04300C] [Medline: 21799072]

8. Granger CL, McDonald CF, Irving L, Clark RA, Gough K, Murnane A, et al. Low physical activity levels and functional decline in individuals with lung cancer. Lung Cancer 2014 Feb;83(2):292-299. [doi: 10.1016/j.lungcan.2013.11.014] [Medline: 24360323]

9. Kasymjanova G, Correa JA, Kreisman H, Dajczman E, Pepe C, Dobson S, et al. Prognostic value of the six-minute walk in advanced non-small cell lung cancer. J Thorac Oncol 2009 May;4(5):602-607 [FREE Full text] [doi: 10.1097/JTO.0b013e31819e77e8] [Medline: 19276833]

10. Liu XL, Tan JY, Wang T, Zhang Q, Zhang M, Yao L, et al. Effectiveness of home-based pulmonary rehabilitation for patients with chronic obstructive pulmonary disease: a meta-analysis of randomized controlled trials. Rehabil Nurs 2014;39(1):36-59. [doi: 10.1002/rnj.112] [Medline: 23780865]

11. Grosbois JM, Gicquello A, Langlois C, Le Rouzic O, Bart F, Wallaert B, et al. Long-term evaluation of home-based pulmonary rehabilitation in patients with COPD. Int J Chron Obstruct Pulmon Dis 2015;10(1):2037-2044 [FREE Full text] [doi: 10.2147/COPD.S90534] [Medline: 26445534]

12. Ryerson CJ, Cayou C, Topp F, Hilling L, Camp PG, Wilcox PG, et al. Pulmonary rehabilitation improves long-term outcomes in interstitial lung disease: a prospective cohort study. Respir Med 2014 Jan;108(1):203-210 [FREE Full text] [doi: 10.1016/j.rmed.2013.11.016] [Medline: 24332409]

13. Dowman L, Hill CJ, Holland AE. Pulmonary rehabilitation for interstitial lung disease. Cochrane Database Syst Rev 2014 Oct 06(10):CD006322. [doi: 10.1002/14651858.CD006322.pub3] [Medline: 25284270]

14. Temel JS, Greer JA, Goldberg S, Vogel PD, Sullivan M, Pirl WF, et al. A structured exercise program for patients with advanced non-small cell lung cancer. J Thorac Oncol 2009 May;4(5):595-601 [FREE Full text] [doi: 10.1097/JTO.0b013e31819d18e5] [Medline: 19276834]

15. Quist M, Rørth M, Langer S, Jones LW, Laursen JH, Pappot H, et al. Safety and feasibility of a combined exercise intervention for inoperable lung cancer patients undergoing chemotherapy: a pilot study. Lung Cancer 2012 Feb;75(2):203-208. [doi: 10.1016/j.lungcan.2011.07.006] [Medline: 21816503]

16. Olivier C, Grosbois JM, Cortot AB, Peres S, Heron C, Delourme J, et al. Real-life feasibility of home-based pulmonary rehabilitation in chemotherapy-treated patients with thoracic cancers: a pilot study. BMC Cancer 2018 Dec 13;18(1):178 [FREE Full text] [doi: 10.1186/s12885-018-4102-6] [Medline: 29433474]

17. Jastrzębski D, Maksymiak M, Kostorz S, Bezubka B, Osmanska I, Młynczak T, et al. Pulmonary rehabilitation in advanced lung cancer patients during chemotherapy. Adv Exp Med Biol 2015;861:57-64. [doi: 10.1007/5584 2015 134] [Medline: $\underline{26017725]}$

18. Mosa AS, Yoo I, Sheets L. A systematic review of healthcare applications for smartphones. BMC Med Inform Decis Mak 2012;12:67 [FREE Full text] [doi: 10.1186/1472-6947-12-67] [Medline: 22781312]

19. Dorsey ER, Yvonne Chan YF, McConnell MV, Shaw SY, Trister AD, Friend SH. The use of smartphones for health research. Acad Med 2017 Feb;92(2):157-160. [doi: 10.1097/ACM.0000000000001205] [Medline: 27119325]

20. Shallwani SM, Simmonds MJ, Kasymjanova G, Spahija J. Quality of life, symptom status and physical performance in patients with advanced non-small cell lung cancer undergoing chemotherapy: an exploratory analysis of secondary data. Lung Cancer 2016 Dec;99:69-75. [doi: 10.1016/j.lungcan.2016.06.018] [Medline: 27565917]

21. Wong WS, Fielding R. Quality of life and pain in Chinese lung cancer patients: is optimism a moderator or mediator? Qual Life Res 2007 Feb;16(1):53-63. [doi: 10.1007/s11136-006-9106-z] [Medline: 17091368]

22. Wu Y, Fukuoka M, Mok TS, Saijo N, Thongprasert S, Yang JC, et al. Tumor response and health-related quality of life in clinically selected patients from Asia with advanced non-small-cell lung cancer treated with first-line gefitinib: post hoc analyses from the IPASS study. Lung Cancer 2013 Aug;81(2):280-287. [doi: 10.1016/j.lungcan.2013.03.004] [Medline: 23540718]

23. Uhm KE, Yoo JS, Chung SH, Lee JD, Lee I, Kim JI, et al. Effects of exercise intervention in breast cancer patients: is mobile health (mHealth) with pedometer more effective than conventional program using brochure? Breast Cancer Res Treat 2017 Feb;161(3):443-452. [doi: 10.1007/s10549-016-4065-8] [Medline: 27933450] 
24. Pradella CO, Belmonte GM, Maia MN, Delgado CS, Luise APT, Nascimento OA, et al. Home-based pulmonary rehabilitation for subjects with COPD: a randomized study. Respir Care 2015 Apr;60(4):526-532. [doi: 10.4187/respcare.02994] [Medline: 25269680]

25. Maltais F, Bourbeau J, Shapiro S, Lacasse Y, Perrault H, Baltzan M, Chronic Obstructive Pulmonary Disease Axis of Respiratory Health Network, Fonds de recherche en santé du Québec. Effects of home-based pulmonary rehabilitation in patients with chronic obstructive pulmonary disease: a randomized trial. Ann Intern Med 2008 Dec 16;149(12):869-878. [doi: 10.7326/0003-4819-149-12-200812160-00006\}] [Medline: 19075206]

26. Huang Y, Zheng H, Nugent C, McCullagh P, Black N, Burns W, et al. An orientation free adaptive step detection algorithm using a smart phone in physical activity monitoring. Health Technol 2012 Oct 26;2(4):249-258 [FREE Full text] [doi: $10.1007 / \mathrm{s} 12553-012-0035-2]$

27. Naqvi NZ, Kumar A, Chauhan A, Sahni K. International Journal on Computer Science and Engineering. 2012 May. Step counting using smartphone-based accelerometer URL: http://www.enggjournals.com/ijcse/doc/IJCSE12-04-05-266.pdf [accessed 2018-11-30] [WebCite Cache ID 74JNgJTGh]

28. Nishiguchi S, Yamada M, Nagai K, Mori S, Kajiwara Y, Sonoda T, et al. Reliability and validity of gait analysis by android-based smartphone. Telemed J E Health 2012 May;18(4):292-296. [doi: 10.1089/tmj.2011.0132] [Medline: 22400972]

29. Carlson RH, Huebner DR, Hoarty CA, Whittington J, Haynatzki G, Balas MC, et al. Treadmill gait speeds correlate with physical activity counts measured by cell phone accelerometers. Gait Posture 2012 Jun;36(2):241-248 [FREE Full text] [doi: 10.1016/j.gaitpost.2012.02.025] [Medline: 22475727]

\author{
Abbreviations \\ 6MWD: 6-min walking distance \\ 6MWT: 6-min walk test \\ COPD: chronic obstructive lung disease \\ ED: emergency department \\ Questionnaire-C30 \\ $\mathbf{F E V}_{\mathbf{1}}$ : forced expiratory volume in 1 second \\ FVC: forced vital capacity \\ GAD-7: Generalized Anxiety Disorder-7 \\ HR: heart rate \\ ILD: interstitial lung disease \\ IoT: Internet of Things \\ NRS: numeric rating scale \\ NSCLC: non-small cell lung cancer \\ PHQ-9: Patient Health Questionnaire-9 \\ PR: pulmonary rehabilitation \\ QoL: quality of life
}

ECOG-PS: Eastern Cooperative Oncology Group-Performance Status

EORTC QLQ-C30: European Organization for Research and Treatment of Cancer Quality of Life

\author{
Edited by G Eysenbach; submitted 19.05.18; peer-reviewed by YR Park, SY Shin, T Wang; comments to author 03.09.18; revised \\ version received 23.10.18; accepted 10.11.18; published 04.02.19 \\ Please cite as: \\ Park S, Kim JY, Lee JC, Kim HR, Song S, Kwon H, Ji W, Choi CM \\ Mobile Phone App-Based Pulmonary Rehabilitation for Chemotherapy-Treated Patients With Advanced Lung Cancer: Pilot Study \\ JMIR Mhealth Uhealth 2019;7(2):e11094 \\ URL: http://mhealth.jmir.org/2019/2/e11094/ \\ doi: $10.2196 / 11094$ \\ PMID: 30714943
}

(CSojung Park, Ji Youn Kim, Jae Cheol Lee, Hyeong Ryul Kim, Seungjae Song, Hee Kwon, Wonjun Ji, Chang Min Choi. Originally published in JMIR Mhealth and Uhealth (http://mhealth.jmir.org), 04.02.2019. This is an open-access article distributed under the terms of the Creative Commons Attribution License (https://creativecommons.org/licenses/by/4.0/), which permits unrestricted use, distribution, and reproduction in any medium, provided the original work, first published in JMIR mhealth and uhealth, is properly cited. The complete bibliographic information, a link to the original publication on http://mhealth.jmir.org/, as well as this copyright and license information must be included. 